https://helda.helsinki.fi

\title{
Mapping the online songbird trade in Indonesia
}

\section{Fink, Christoph}

2021-09

Fink , C , Toivonen , T , Correia , R A \& Di Minin , E 2021 , ' Mapping the online songbird trade in Indonesia ', Applied Geography , vol. $134,102505$.

https://doi.org/10.1016/j.apgeog.2021.102505 , https://doi.org/10.31235/osf.io/mxkgq

http://hdl.handle.net/10138/333099

https://doi.org/10.1016/j.apgeog.2021.102505

cc_by

publishedVersion

Downloaded from Helda, University of Helsinki institutional repository.

This is an electronic reprint of the original article.

This reprint may differ from the original in pagination and typographic detail.

Please cite the original version. 


\title{
Mapping the online songbird trade in Indonesia
}

\author{
Christoph Fink ${ }^{\text {a,b, }}$, Tuuli Toivonen ${ }^{\text {b,c,d }}$, Ricardo A. Correia ${ }^{\text {a,b,e }}$, Enrico Di Minin ${ }^{\text {a,b,f }}$ \\ ${ }^{a}$ Helsinki Lab of Interdisciplinary Conservation Science, Department of Geosciences and Geography, University of Helsinki, Finland \\ ${ }^{\mathrm{b}}$ Helsinki Institute of Sustainability Science, University of Helsinki, Finland \\ ${ }^{\mathrm{c}}$ Digital Geography Lab, Department of Geosciences and Geography, University of Helsinki, Finland \\ ${ }^{\mathrm{d}}$ Department of Zoology, Conservation Science Group, University of Cambridge, Cambridge, UK \\ ${ }^{\mathrm{e}}$ DBIO \& CESAM - Centre for Environmental and Marine Studies, University of Aveiro, Portugal \\ ${ }^{\mathrm{f}}$ School of Life Sciences, University of KwaZulu-Natal, Durban, South Africa
}

\section{A R T I C L E I N F O}

\section{Keywords:}

Wildlife trade

Online marketplaces

Digital conservation

Conservation culturomics

Conservation geography

Pet trade

\begin{abstract}
A B S T R A C T
Wildlife trade, when unsustainable, can be an important threat to biodiversity conservation. In this contribution, we explored the use of digital data to investigate the online market for songbirds in Indonesia, where keeping pet songbirds is a deeply rooted cultural practice. We examined the spatial characteristics of three dimensions of the songbird trade using data from online sources: birdwatchers' sightings as a proxy for the supply of the songbird market, small advertisements from an online marketplace platform, representing the trade itself and its transactions, and videos by pet songbird owners to represent the demand side of the songbird market. We found that, geographically, these three stages of the songbird supply chain did not overlap, which potentially hints at the roles extended transport networks and commercial captive breeding play for the songbird trade. The trade was not confined to major cities but spread out through the country, indicating both a possible democratisation of the trade (i.e. a larger group of sellers, and consumers selling to consumers) and an opportunity to observe previously covert parts of the trade. We further found that the asking prices on online marketplaces were significantly higher than the prices stated in an independently carried out consumer survey and discuss possible reasons for these differences. Data from digital sources can give rich insights into the spatial, temporal and taxonomic structure of wildlife trade, can help understand the motivations of buyers and sellers, and can help direct wildlife trade towards a more sustainable fashion. Our methodology toolbox that allows automatic and continuous monitoring of online marketplaces, includes data preparation and cleaning, and follows the highest standards of data privacy principles, is openly available.
\end{abstract}

\section{Introduction}

Keeping songbirds as pets is a deeply-rooted social and cultural practice in Southeast Asia, in particular on the Indonesian islands of Java and Bali (Jepson, 2010; Marshall et al., 2020a). A central notion of this practice is an appreciation for the perceived beauty and exoticism of birds' songs (Chng et al., 2015), which culminates in songbird singing competitions at local, regional, and national levels (Jepson et al., 2011). Mastering bird husbandry and breeding is a highly valued cultural technique (Jepson, 2010). A recent household survey found that $31 \%$ of households kept birds, and estimated that 70 million cage-birds are kept on Java, alone (Marshall et al., 2020a). Another household survey a decade earlier had found that $35.1 \%$ of Indonesian households owned a pet bird and that birds were the most popular pets (Jepson \& Ladle,
2009).

The cultural practice of bird-keeping has taken on dimensions that manifest a threat to the survival of many highly sought-after species (Harris et al., 2017; Jepson \& Ladle, 2005; Lee et al., 2016). There are clear indications that rarity (e.g. Critically Endangered species) is a sought-after characteristic when pet owners choose a species (Harris et al., 2015), thereby putting threatened species at an even higher risk of extinction. In the centre of this "Asian songbird crisis" (Lee et al., 2016), itself part of a larger biodiversity crisis throughout Southeast Asia (Butchart et al., 2010; Di Minin, Brooks, et al., 2019; Sodhi et al., 2004) and at one of the epicentres of an unsustainable global wildlife trade (Maxwell et al., 2016), is a thriving pet market for songbirds (Bergin et al., 2018; Chng et al., 2015; Leupen et al., 2018; Shepherd et al., 2016) that serves a predominately urban audience (Jepson \& Ladle, 2009;

\footnotetext{
* Corresponding author. Department of Geosciences and Geography, University of Helsinki, 00014 Helsinki, Finland.

E-mail address: christoph.fink@helsinki.fi (C. Fink).
} 
Marshall et al., 2020a). Many specimens are still wild-caught even if they could potentially be bred in captivity (Chng, Krishnasamy, \& Eaton, 2018; Jepson \& Ladle, 2009). Most species are protected by national regulations and international agreements (Chng, Krishnasamy, \& Eaton, 2018; CITES, 2020; Ministry of Environment and Forestry, Republic of Indonesia, 2018), and many are classified in the IUCN Red List as threatened ('Vulnerable', 'Endangered' or 'Critically Endangered', IUCN, 2020a). This renders the trade in many species illegal and potentially unsustainable, but sellers continue to openly display such animals in markets (Nijman et al., 2018). This indicates insufficient enforcement of existing regulations, hints at a lack of awareness for animal welfare in the public, and uncovers the deep roots of the associated cultural practices.

The motivations behind acts of unsustainable use of wildlife typically are complex and multi-faceted (Hinsley \& 't Sas-Rolfes, 2020). When use of wildlife is rooted in traditional cultural practices, demand reduction strategies must be carefully informed and targeted, and convey truthful, not overly simplified, messages (Dang Vu \& Nielsen, 2021). Trying to counter use of wildlife that is rooted in cultural practices exclusively with law enforcement is not a sustainable pathway and has proven unsuccessful (Challender \& MacMillan, 2014). To help direct the songbird trade and the associated cultural traditions towards more sustainable models, detailed knowledge about all aspects of the trade are crucial.

The songbird trade in Indonesia has been investigated using different methods. Market surveys have looked at the trade from a species-specific perspective (Beastall et al., 2016; Bergin et al., 2018; Leupen et al., 2018; Nijman et al., 2018; Shepherd et al., 2016), or with a geographical focus (Aloysius et al., 2020; Chng, Krishnasamy, \& Eaton, 2018; Rentschlar et al., 2018), some combined with expert interviews (Harris et al., 2015), or focussing on the trade's impact on wild populations (Harris et al., 2017). Consumer surveys have shed light on the demand side of the trade (Chng et al., 2015; Jepson \& Ladle, 2009; Marshall et al., 2020a; Rentschlar et al., 2018), and analyses of seizure data assessed the extent of illegal trade and the degree of law enforcement success (Leupen et al., 2018). Increasingly, online studies based either on questionnaires (Siriwat \& Nijman, 2020) or on manually monitoring social media groups (Gunawan \& Noske, 2017; Iqbal, 2015; Leupen et al., 2018; Nijman et al., 2018; Siriwat, 2019) are being carried out. Other studies have sketched the possible actors and networks of a supply chain of the Indonesian songbird trade (Jepson \& Ladle, 2005) and illegal wildlife trade in general (Phelps et al., 2016).

Most studies are characterised by an enormous organisational effort and a high workload that yield but a snapshot in time and space. Scholars have been calling for cost-effective ways to monitor bird markets (Chng et al., 2015; Harris et al., 2015), for instance as an early warning system that would allow enhancing direct field monitoring of especially threatened species (Harris et al., 2015). Chng et al. (2015) warn that, while regular monitoring is crucial to uncover market dynamics and species composition, traditional methods of market surveying might arouse suspicion among traders.

Similar to other illegal trade in wildlife, a large portion of the market in songbirds has moved online; this move online might be further accelerated by the restrictions imposed against the current global COVID-19 pandemic. The illegal market in ivory, rhino horn and similar wildlife commodities saw a shift to social media (e.g. Facebook, WhatsApp; see Yu \& Jia, 2015), these channels also play an important role in the pet bird trade (Siriwat \& Nijman, 2020). Automated identification of online content can help support long-term monitoring efforts to study the supply chain of wildlife trade and the actors involved (Di Minin et al, 2018, 2019b).

Our objectives were to explore the utility of digital data to investigate the supply chain of the Indonesian songbird trade and its spatial and temporal characteristics, and to develop a methodological toolbox and toolchain for automatic continuous monitoring, that make use of novel methods from computer vision and computational linguistics. We collected data from three sources that represent different stages of the supply chain: sales posts on an online marketplace, bird sightings reported to a birdwatchers' platform, and home videos of pet bird owners posted to a video platform. We then used spatial statistics to investigate the spaces of three stages of the supply chain of the Indonesian online trade in songbirds, represented by the three data sources, and analysed the marketplace's asking prices. We expected locations related to pet songbirds and to the trade in songbirds to be found throughout the country with a pronounced emphasis on urban areas (cf. Jepson et al., 2011; Marshall et al., 2020a), and locations of wild bird sightings mostly confined to the species ranges reported in the BirdLife International and Handbook of the Birds of the World (2019) and on the IUCN Red List (IUCN, 2020b). Further, we anticipated prices to be higher in more densely populated places, where higher demand would be expected, and at roughly the same levels to those reported in Marshall et al. (2020b).

\section{Data \& Methods}

\subsection{Focal species}

As a case study to introduce our framework, we selected three species of songbirds that are especially vulnerable to the pet trade in Indonesia and other countries in South East Asia.

The straw-headed bulbul (Pycnonotus zeylanicus) is severely threatened by trapping for trade (Lee et al., 2016). The endemic Javan pied starling (Gracupica jalla) is among the most sought-after birds on the Indonesian songbird market (Chng, Krishnasamy, \& Eaton, 2018; Marshall et al., 2020b; Nijman et al., 2021), and there is doubt over the continued existence of wild populations (Birdlife International, 2017). The white-rumped shama (Kittacincla malabarica) is the most frequently mentioned single species in Marshall et al. (2020a, 2020b)'s consumer survey. Its beautiful song and colourful appearance make it a popular species in singing competitions (Jepson \& Ladle, 2009; Leupen et al., 2018). For a detailed description of the focal species, see Supplementary Material.

All three species are listed as highest priority species in the Conservation Strategy for Southeast Asian Songbirds in Trade (Lee et al., 2016), their populations' status in Indonesia is especially dire and they are possibly extinct on Java (IUCN, 2020a; 2020b). All three species can be bred in captivity and are reportedly being captive-bred commercially (Chng et al., 2015; Eaton et al., 2015; Jepson \& Ladle, 2005; Lee et al., 2016). However, in the case of the white-rumped shama and the straw-headed bulbul, it is not clear whether commercial breeding is more than a smokescreen to conceal the real extent to which birds found on markets originate from wild-caught populations (Eaton et al., 2015).

\subsection{Data sources}

\subsubsection{Query keywords}

We used Wikipedia's wikidata database to obtain scientific names, English and Indonesian common names, including alternative spellings, for the three focal species. We then conducted a pilot data collection phase of seven days, after which we semi-automatically identified additional keywords in the text content of small advertisements, video metadata and comments. We used NLTK (Bird, Klein, \& Loper, 2012) to extract n-grams (bi- and trigrams), i.e. words that frequently occur in combination, and list their counts, then carried out manual internet searches to evaluate the usefulness of the 20 most common n-grams. The resulting list of keywords (Table 1 ) selects a set of advertisements, videos and comments for download that pertains to the focal species of this study.

\subsubsection{Small advertisements (OLX.com.id)}

OLX is an online marketplace for small advertisements, operating in various countries around the globe. On its Indonesian page (olx.com. id), we found listings advertising songbirds for sale, amongst them protected species (see below). Listings include photos, asking price and 
Table 1

Query keywords for data collection.

\begin{tabular}{lll}
\hline Javan pied starling & white-rumped shama & straw-headed bulbul \\
\hline javan pied starling & white-rumped shama & straw-headed bulbul \\
gracupica jalla & copsychus malabaricus & pycnonotus zeylanicus \\
jalak suren jawa & kucica hutan & $\begin{array}{l}\text { cucak rawa } \\
\text { jalak uren jawa }\end{array}$ \\
& & cangurawak \\
& barau-barau \\
\hline
\end{tabular}

location. We specifically focussed on online marketplaces rather than social media platforms, on which similar listings can be potentially found, but often require authentication, e.g., for joining closed groups, while the former are publicly accessible.

We developed a tool, olxsearch (Fink, 2020a), to download data and metadata on small advertisements published on the OLX online marketplaces. It downloads the text and image content, as well as date, location, duration of publication and the advertised retail price by scraping the marketplace's web page. Because of the nature of web scraping, we could only retrieve advertisements that were online during the data collection period that lasted from 1 February to July 31, 2020. Overall, this amounted to a raw data set of 1858 small advertisements containing 8838 photos.

\subsubsection{Video metadata and comments (YouTube)}

There is a significant number of videos of songbirds posted to online video platforms, e.g. YouTube (https://youtube.com/). Often, the price or value of an animal is discussed in the comment section underneath a video posting.

We developed a tool, metatube (Fink, 2020b), to download video metadata and comments from YouTube. The software package saves the downloaded data in a relational database that allows relating comments to videos and vice versa. The YouTube application programming interface (API), which metatube uses, allows retrieving all videos and all comments that are online at the time of retrieval. The data we downloaded spans from June 30, 2006 to July 31, 2020, and comprises of 11, 299 videos, and 10,882 comments related to them.

\subsubsection{Birdwatchers' sightings (eBird)}

eBird (https://ebird.org/, Sullivan et al., 2009) is an app and website for birdwatchers that allows them to report their sightings and share them with other enthusiasts and with scientists conducting research on birds. Data from eBird (Sullivan et al., 2009) can be downloaded from the project's web page (http://ebird.com) after registration, if it is used for a specified range of applications, such as scientific research. Data on some species, including the three focal species of this study, are treated with a higher level of confidentiality, for instance, to protect threatened species from being easily located by poachers. To obtain data on such species, researchers must undergo manual review. We obtained a total of 13,320 reports of birdwatchers' observations of the three study species, which date from March 2, 1969 to January 31, 2020 (the majority of observations have been reported since 2003). The obtained records cover the entire ranges of the focal species. For the straw-headed bulbul, besides Indonesia this also includes Malaysia and Singapore, while the range of the white-rumped shama extends until the Indian subcontinent in the West and the southern slopes of the Himalaya in the North.

\subsection{Data preparation}

The different data sources required a different level of pre-processing (Fig. 1). While bird observation data required only file format conversion, both marketplace data and video metadata required extensive data preparation. In particular, we had to i) identify marketplace advertisements that did not offer a bird for sale and discard them, ii) extract

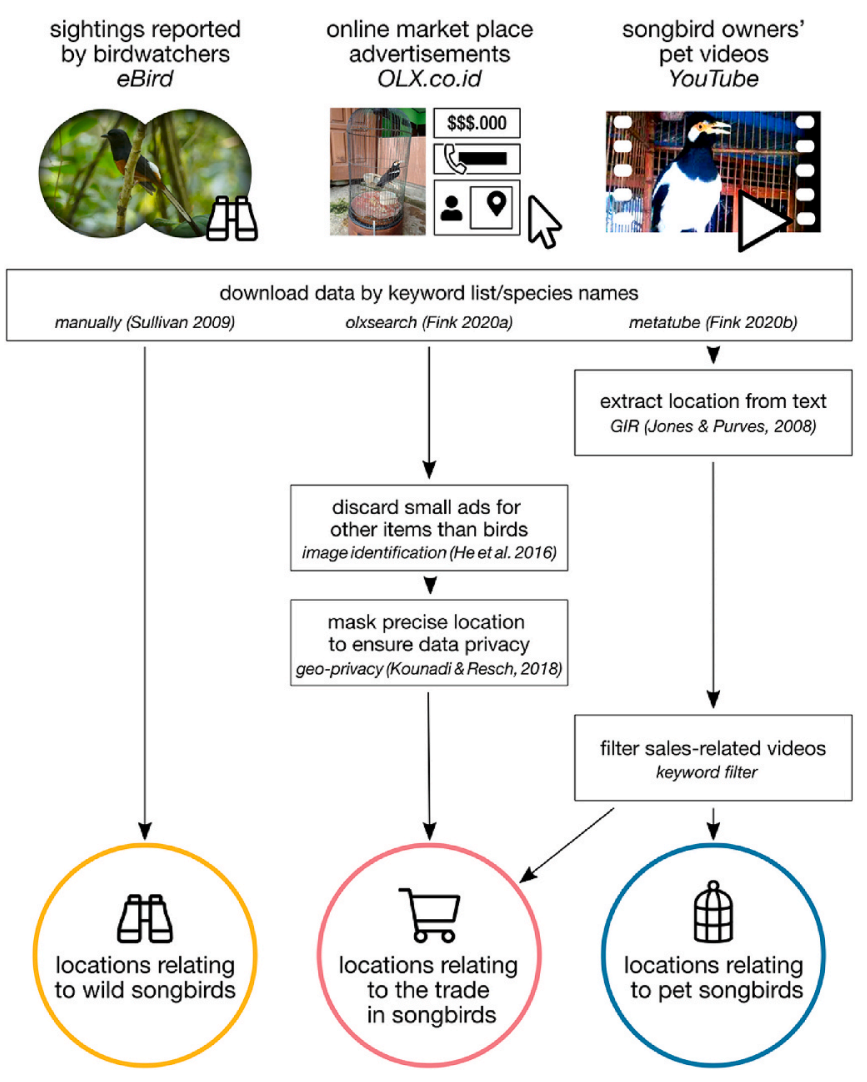

Fig. 1. Data collection and pre-processing workflow. The figure shows the principal steps of data preparation and the tools, techniques and methods used in each step. Data from eBird do not require any pre-processing other than format conversion. Data scraped from online marketplaces (OLX.co.id) and video metadata (YouTube), in contrast, require substantial pre-processing, see Data \& Methods.

geographic locations from video descriptions, iii) separate videos that were likely to relate to an act of sale from videos that were presenting a pastime activity, and iv) assure we honoured ethical and legal data privacy principles (Di Minin et al., 2021).

\subsubsection{Extracting geographic locations from text content (videos)}

Only a small part of digital data sources provide metadata that directly refers to a geographic location. For instance, photos on Flickr and short messages on Twitter can be georeferenced, i.e. tagged with a coordinate pair and thus linked to a location. Not all users decide to enable this feature, and many platforms' APIs do not return precise coordinates, but rather the name of a nearby place (Toivonen et al., 2019). Data from YouTube, i.e. video metadata and comments, typically do not contain either kind of information. However, many of the video titles, descriptions, and comments contain place names. This allowed us to use Geographic Information Retrieval techniques (GIR, Jones \&

Table 2

Number of posts collected, by data source and species.

\begin{tabular}{|c|c|c|c|c|c|}
\hline \multirow[t]{2}{*}{ related to } & \multirow{2}{*}{$\begin{array}{l}\text { data } \\
\text { source }\end{array}$} & \multicolumn{3}{|l|}{ species } & \multirow[b]{2}{*}{ sum } \\
\hline & & $\begin{array}{l}\text { Javan pied } \\
\text { starling }\end{array}$ & $\begin{array}{l}\text { straw- } \\
\text { headed } \\
\text { bulbul }\end{array}$ & $\begin{array}{l}\text { white- } \\
\text { rumped } \\
\text { shama }\end{array}$ & \\
\hline observations & eBird & 7 & 3,325 & 9,988 & 13,320 \\
\hline pets & YouTube & 94 & 31 & 3 & 128 \\
\hline \multirow[t]{2}{*}{ trade } & OLX & 1,866 & 133 & 243 & 2,242 \\
\hline & YouTube & 139 & 88 & 18 & 245 \\
\hline sum & & 2,106 & 3,577 & 10,252 & 15,935 \\
\hline
\end{tabular}




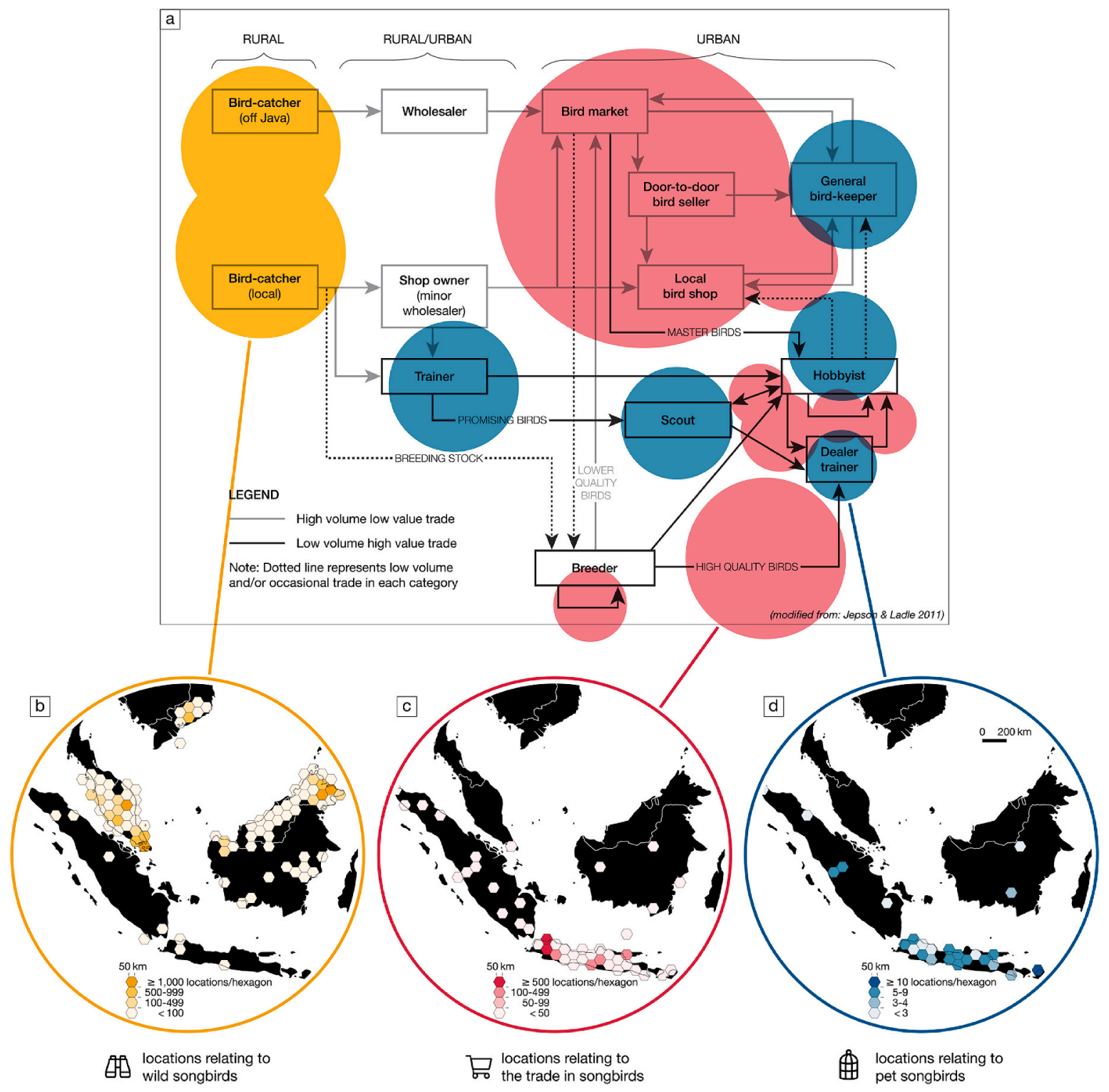

Fig. 2. The supply chain of Indonesia's online songbird trade and its spaces and network. The places in which songbirds are spotted in the wild by birdwatchers, where they are advertised on online marketplaces, and where they are presented online as pets represent three mostly non-overlapping spaces (panels b-d). These data, obtained from digital sources (see Data \& Methods) allow new insights on different actors in the supply chain network of the songbird trade (panel a, modified from Jepson et al., 2011). Especially noteworthy are the insights gained from online marketplace data (panel c, highlighted areas in red in panel a), which are significantly more comprehensive than traditional market surveys that typically focus on physical marketplaces. (For interpretation of the references to colour in this figure legend, the reader is referred to the Web version of this article.)

Table 3

Spatial correlation between different indicators. We summarised the counts of small advertisements, pet home videos and birdwatchers' observations in a grid of hexagons of $10 \mathrm{~km}$ side length, calculated the mean asking price of small advertisements contained in each cell and the population density estimate for 2020 , as reported in the Gridded Population of the World data set (Doxsey-Whitfield et al., 2015). We also computed the distances of each small ad, pet home video and bird observation from the species range of the respective species as reported by the IUCN red list (IUCN, 2020b). The Pearson correlation coefficients were computed using SciPy 1.5.2 (Virtanen et al., 2020). Asterisks *, **, and *** refer to p-values at $0.1,0.05$, and 0.01 levels, respectively.

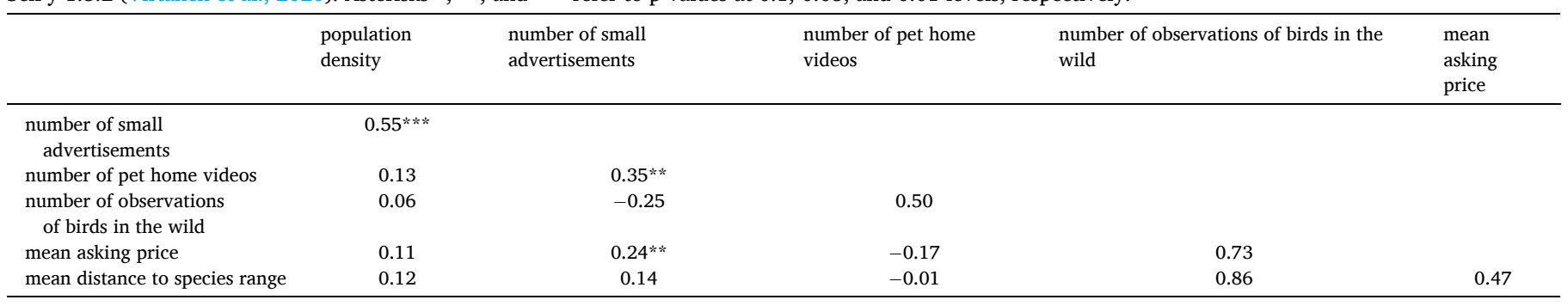




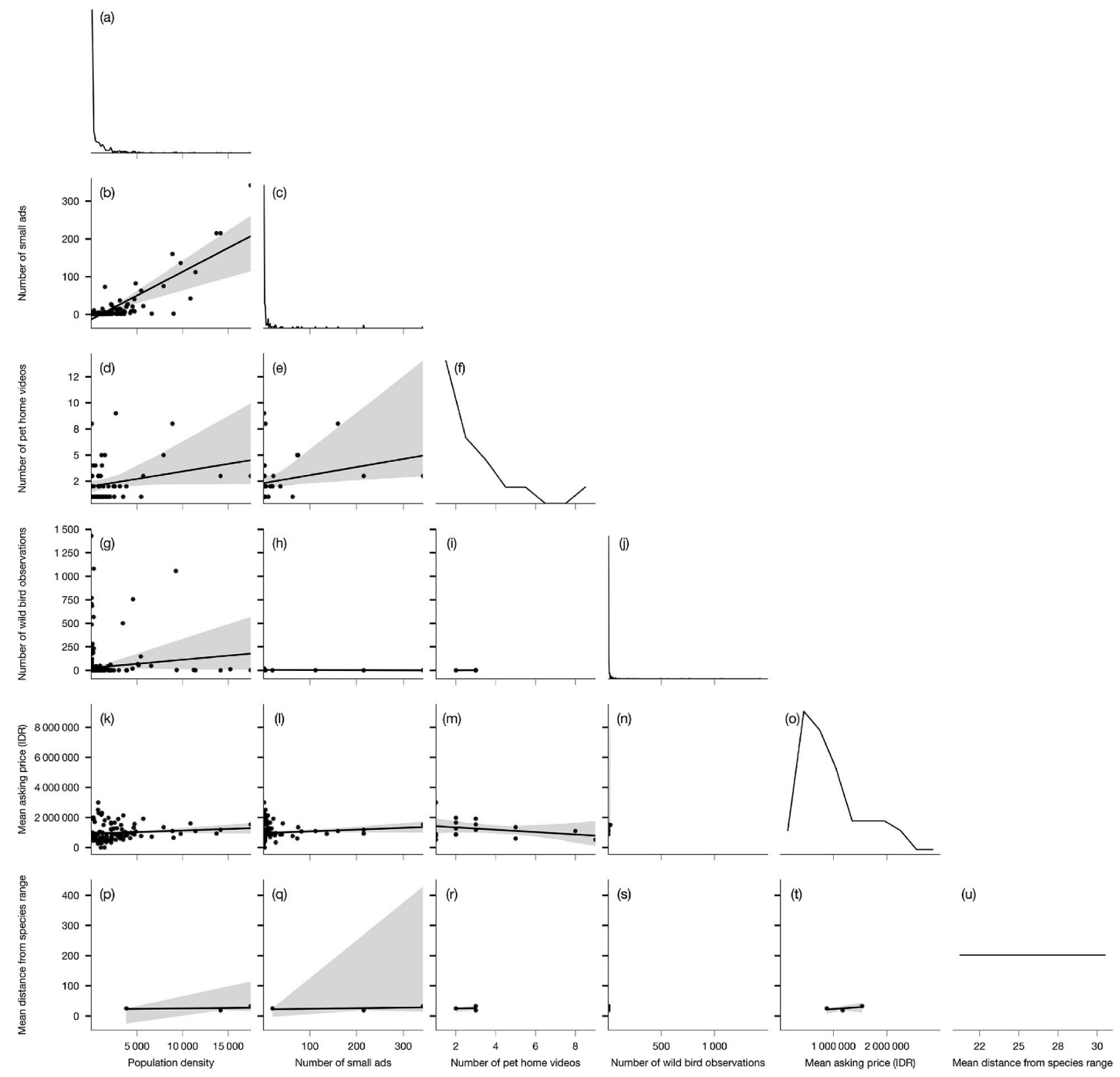

Fig. 3. Spatial correlation between different indicators. We summarised the counts of small advertisements, pet home videos and bird watchers' observations in a grid of hexagons of $10 \mathrm{~km}$ side length. We then calculated the mean asking price of small advertisements contained in each cell and the population density estimate for 2020, as reported in the Gridded Population of the World data set (Doxsey-Whitfield et al., 2015), and plotted the correlations between these variables and calculated Pearson correlation coefficients.

The most striking indication visible in this figure is the correlation between population density and the number of small advertisements posted (Panel (b), a Pearson correlation coefficient of 0.55 at a p-value of 0.01 , see also Table 3). This correlation suggests that online trade in songbirds occurs where people live, rather than where wild birds are observed (also compare panel (h)). It further suggests that the online trade provides a more equally distributed service across the country, as opposed to a more traditional trade in songbirds that concentrates on few markets in major cities, with the further distribution networks out of view of researchers.

Purves, 2008). Our method comprised of two steps: first, we identified and extracted place names using Named Entity Recognition (NER) tools. NER is a natural language processing method to extract names, including names of geographic places, from text (Leidner \& Lieberman, 2011). NER tools are readily available for all major languages, but mainstream tools do not cover the Indonesian language. Instead, we used NERGRIT, a NER model for the Indonesian language developed by Fahmi et al. (2019), that is trained on data from Wikipedia articles, and for which the authors report an F1 score of 0.8 . Second, we georeferenced the identified geographic place names, i.e. added a geographic coordinate pair to each place name. We used Geocoder (Carriere, 2013) with a custom instance of the Nominatim (https://nominatim.org) gazetteer, based on OpenStreetMap data (data snapshot from March 5,
2020), and selected the highest rank match as returned by the gazetteer.

\subsubsection{Separating sales from hobby videos}

All videos for which we downloaded metadata relate to the three focus species of the study. However, some videos are presenting or celebrating bird-keeping as a hobby, while others are openly or covertly offering an animal for sale. In the comments below many videos, viewers speculate over the market value of the bird shown, indicating their interest in a transaction. For this study, we consider both videos selling a bird and videos with a discussion of a possible price to be data points relating more to the trade in songbirds, and all other videos to relate more to pet-keeping. To separate the one from the other, we matched them against a list of keywords that pertain to sales-related posts 

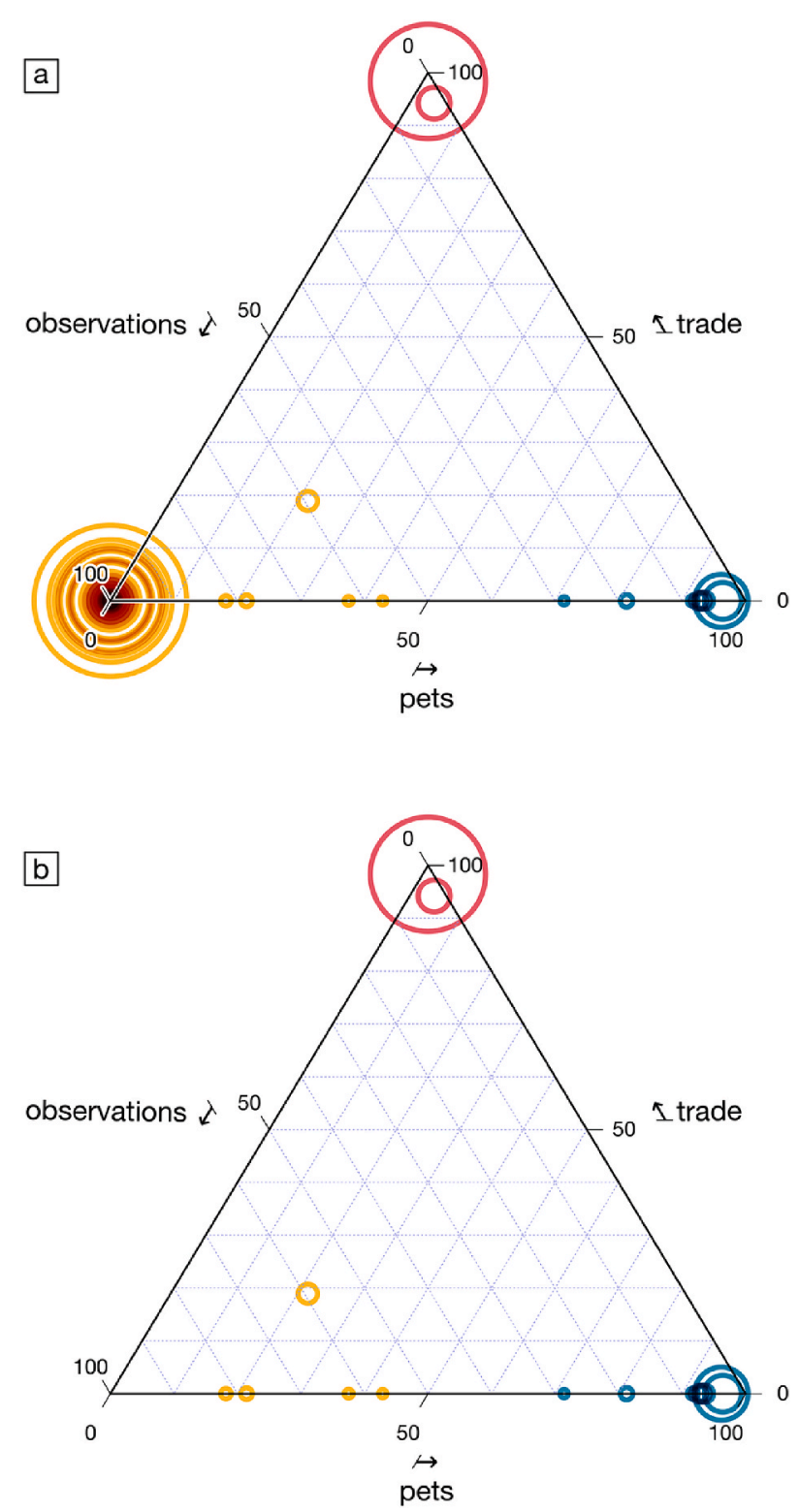

Fig. 4. Composition of (spatial) clusters. For each spatial cluster obtained using A-DBSCAN, the plots show the ratio of cluster members between the three data categories wild songbirds, trade in songbirds, and pet songbirds. Panel b) excludes clusters that contained data points of only one category. Even then, each cluster is clearly dominated by one category, indicating that the three data categories are found in different places.

(Table S.1 in Supplementary Material). We compiled the list in an iterative and recursive process: we searched the description of videos suspected to offer birds for probable keywords, added them to the initial keyword list, then evaluated a sample of the (new) search result set to eliminate keywords producing a large number of false positives.

\subsubsection{Identifying birds in advertisement photos}

Many place names or names of objects contain species names. The descriptions or title of some of the small advertisements posts matched bird species names, even though the advertised merchandise was not a bird. To filter out other sales items, we used a ResNet50 model (He et al., 2016, pp. 770-778) trained on ImageNet data (Deng et al., 2009) to identify the content of photos attached to each post. We examined the top five predictions for each photo of each post and kept every post, for which at least one photo was predicted to contain a hyponym, i.e. a linguistic sub-category, of bird. We chose this path of matching

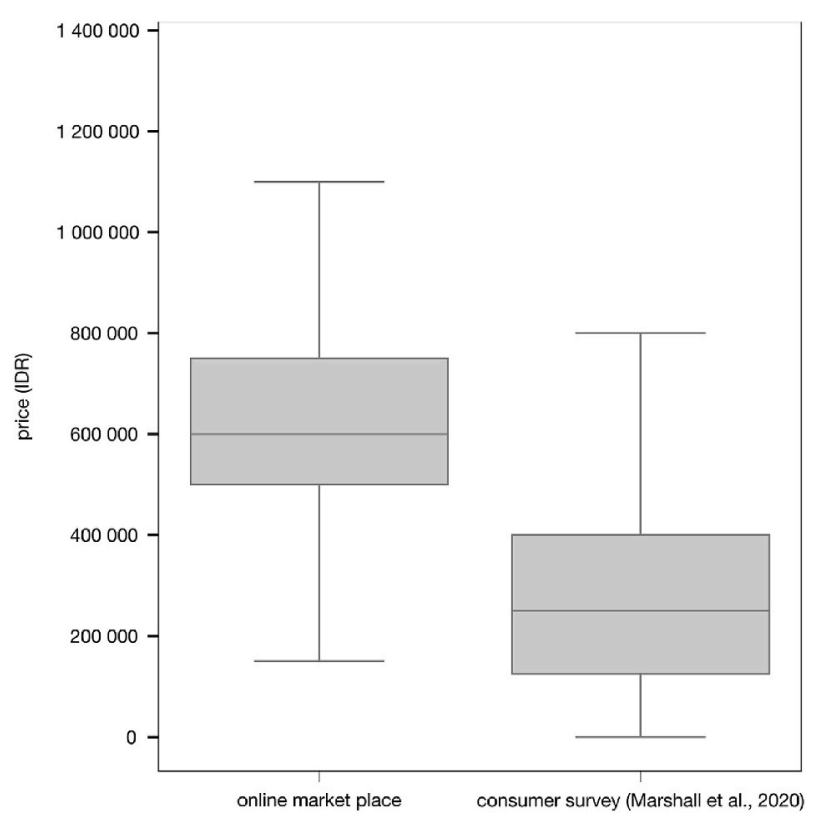

Fig. 5. Prices for songbirds as found on an online marketplace and in a consumer survey (Marshall et al., 2020b). Before plotting the data, we discarded outliers in both data sets (see Data \& Methods). Prices are reported in Indonesian rupiah (IDR).

hyponyms, because, similar to people, ImageNet frequently fails to identify exact species, but reliably identifies on a higher taxonomic level. In some instances, ImageNet failed to identify a bird due to the visual dominance of its cage, which is why we considered images showing a cage to advertise a bird for sale (ImageNet does not have a category cage, but identifies cages as one of the visually similar categories prison, shopping cart or shopping basket). We used NLTK (Bird et al., 2012) to identify hyponyms and Keras (Chollet \& others, 2015) for image identification.

\subsubsection{Data privacy}

Working with digital data requires diligent measures to protect the right to privacy of any person that is potentially contained in any data set used (Di Minin et al., 2021), both in order to fulfil national and supranational data protection laws, such as the European Unions' General Data Privacy Regulations (GDPR), and to live up to ethical standards for research. Measurements that are both effective and easy to implement are data minimisation, i.e. discarding all data that is not strictly required for analysis as early as possible, and pseudonymisation, i.e. replacing original identifiers with randomised identifiers so a data record cannot be traced to the person to whom it relates (Di Minin et al., 2021). We carried out both data minimisation and pseudonymisation, However, an indirect identifier remained: the location of a seller might enable to identify them, their customers, or, worse, wrongly identify someone uninvolved in the songbird trade. To protect people's right to privacy, we masked the precise locations of small advertisement posts. Per Kounadi and Resch's (2018) recommendations, we followed the concept of $k$-anonymity. K-anonymity refers to ensuring that any attempt to identify a person from a given data set would result in a result set of at least $k$ persons. Here, we selected $k=10000$ - which means each data record has to be masked in such a way that it cannot be narrowed down to less than 10,000 people.

Since geolocation is the only attribute in our data set that refers to personal information we were able to use population density data (Gridded Population of the World version 4, Doxsey-Whitfield et al., 2015) to translate this location to a random location within a circle containing a minimum population of $k=10000$ inhabitants. We carried out this masking operation using PostgreSQL/PostGIS, and kept multiple 
records from the same location together (at a new, masked location), in order to correctly depict multiple advertisements from the same location. We chose not to mask the locations of bird observations as they do not represent personal information, nor the locations of videos, since they contain only approximate geolocation.

\subsection{Spatial correlations}

To investigate the spatial correlation between the links of the songbird trade supply chain, and the influence of population density and distance from species ranges on the trade, we summarised the counts of small advertisements, pet home videos and birdwatchers' observations in a grid of hexagons of $10 \mathrm{~km}$ side length. We calculated the mean asking price of small advertisements contained in each cell and the population density estimate for 2020, as reported in the Gridded Population of the World data set (Doxsey-Whitfield et al., 2015). We also computed the distances of each small advertisement, pet home video and bird observation from the species range of the respective species as reported by the IUCN red list (IUCN, 2020b). Then, we used SciPy (Virtanen et al., 2020) to calculate Pearson correlation coefficients between the variables, which had to be log-transformed to be normally distributed.

\subsection{Spatial clusters and their composition}

We then used A-DBSCAN (Arribas-Bel et al., 2019) to cluster all locations of bird observations, online marktplace advertisements and pet owners' videos. Since DBSCAN algorithms generally are sensitive to a correct estimation of its parameters $\varepsilon$ and minimum number of points (Schubert et al., 2017), we estimated optimal parameters in a separate step. For this, we iterated over a range of appropriate values for both parameters, and assessed goodness-of-fit and indicators of cluster completeness and coverage, and settled for $\varepsilon=14 \mathrm{~km}$ and a minimum number of 6 points per cluster (see Figure S.2 in the Supplementary Material).

After clusters were formed, we looked at the composition of each cluster by plotting the share of cluster members originating from each of the three input data sources in a ternary chart using Matplotlib (Hunter, 2007) and python-ternary (Harper et al., 2015).

\subsection{Prices and price distribution}

The marketplace data contained information on the asking price of advertised birds. We used PySAL-esda (Rey \& Anselin, 2007) to compute global Moran's I values to test prices for spatial autocorrelation, both for each species individually and for all species combined. As we were dealing with point data (and thus no other neighbourhood relationships could be established), we used weights based on a kernel density tree.

We also compared the prices found in online marketplace data with those reported in a recent consumer survey (Marshall et al., 2020a), and tested the significance of the difference in prices using Welch's $t$-test.

\section{Results}

After all data preparation steps we retained a total of 15,935 data records, of which 13,320 refer to sightings of wild birds, 2487 to the trade in songbirds, and 128 to owning pet songbirds (see Table 2). The data is imbalanced concerning species and categories: for instance, the Javan pied starling is referred to in 2,005 records relating to trade but has only been sighted by birdwatchers seven times. In contrast, we found only 261 posts offering white-rumped shama for sale, while birdwatchers spotted it 9,988 times. The three data sources exhibit distinct spatial patterns (Fig. 2). Note that the data cover different periods, see Data sources.

\subsection{Spatial correlations, spatial clusters and their composition}

We found a highly significant (at a p-value $<0.01$ ) positive correlation of 0.55 between population density and the number of small advertisements for songbirds on the online marketplace platform. The number of small advertisements correlated at a significant level ( $\mathrm{p}<$ 0.05 ) with the number of pet owners' home videos $(0.35)$ and the mean asking price (0.24). There were no other significant correlations in our data set (Table 3, Fig. 3).

A-DBSCAN identified 84 spatial clusters, out of which 69 consisted entirely of data points relating to birdwatchers' observations of wild birds. The remaining clusters were composed of a mix of observation, trade and pet data, but were still dominated by one of these categories (Fig. 4).

It is a most striking result that the activity spaces of the supply (represented by bird sightings), the transactions (represented by online small advertisements) and the demand (represented by pet owners' videos) of the songbird trade do not overlap (Fig. 4b). Equally noteworthy, trade correlates well with population density and (less strongly) with consumer demand (Table 3, Fig. 3). Charting the collected data in maps supports both results (Fig. 2b-d), with the most wild birds observed on Borneo (Kalimantan) and the Malayan peninsula, sales posts situated in eastern and central Java, and data related to petkeeping in central Java and on Bali (cf. Fig. 3 in Leupen et al., 2018).

\subsection{Prices, and price distribution}

Prices on online marketplaces were not spatially autocorrelated, i.e. they were randomly distributed, with a global Moran's I value of 0.094 at a significance level of $\mathrm{p}<0.001$. Grouped by species, global Moran's I was 0.039 for Javan pied starlings $(\mathrm{N}=1,536, \mathrm{p}<0.001), 0.035$ for straw-headed bulbuls $(\mathrm{N}=106, \mathrm{p}<0.22)$, and 0.056 for white-rumped shamas $(\mathrm{N}=196, \mathrm{p}<0.07)$.

We found that the asking prices for songbirds as advertised on the marketplace platform were significantly higher than the prices reported by bird owners in the consumer survey carried out by Marshall et al. (2020a) (cf. Fig. 5). After removing outliers from each data set (prices lower than Q25 - $(1.5 \times$ IQR) or greater than Q75 + $(1.5 \times$ IQR $)$, where Q25 and Q75 are the first and third quartiles, respectively, and IQR the interquartile range), the median prices were $600,000 \pm 188,604$ IDR (online marketplace, approx. 36 EUR) and 250,000 $\pm 229,075$ IDR (consumer survey, approx. 15 EUR), respectively. A Welch's $t$-test indicated the difference between the prices from the consumer survey and the online marketplace data is highly significant at a p-value $<0.001$.

Prices were not spatially autocorrelated but rather distributed randomly. The prices we observed were significantly higher than the prices reported in a recent consumer survey.

\section{Discussion}

In this study, we explored the use of digital data to assess the trade in songbirds in Indonesia, especially in online marketplaces. To our knowledge, our contribution is the first to collect a continuous time series of all sales posts on a marketplace platform in an automated manner, and relate these data to observations in the wild, and to data pertaining to pet ownership. It is thus the first contribution to investigate multiple steps in the supply chain of the online trade in songbirds. From our exploratory results, we were able to draw some preliminary conclusions:

A critical innovation of our approach is that our data contain spatial information. This enabled us to investigate the songbird trade's inherent spatiality. We examined the spatial characteristics of three dimensions of the songbird trade: (1) the wild population of birds, representing (part of) the supply of the songbird market, (2) small advertisements from an online marketplace platform, representing the trade itself and its 
transactions, and (3) videos by pet songbird owners, representing (part of) the demand side of the songbird market. We found that the spaces of these stages of the online songbird trade's supply chain do not overlap extensively. The clear distinction between where wild birds are observed and where birds are offered for sale, while unsurprising, suggests that the advertised animals must originate from captive-breeding or from other countries. If the supply for the songbird market indeed comes from (local) captive-breeding, it could help reduce the pressure on wild populations. An international trade in songbirds, on the other hand, might be indicative of extended networks involved in the distribution of captured birds to points of sale. Understanding this part of the supply chain network, and especially its dependency on means of transport or breeding facilities, might offer leverage points for intercepting the trade, but digital data do not seem to be able to lift the curtain on it. That notwithstanding, the descriptions and images collected can help direct future research, which should also pay critical attention to the spatial distinction between the trade and the demand.

The spatial distribution of small advertisements correlates with population density. Songbirds are offered for sale where people live. Their trade is spread out through the country, and is equally accessible to people in cities and in the countryside. This might mark a degree of democratisation of the trade, in which a second-hand market between pet owners is enabled, and in which the established trade networks are losing significance (cf. also Siriwat \& Nijman, 2020). Whether travelling salespeople and other distribution networks are being replaced or rather complemented, and whether that, in turn, means a change in trade, demand and off-take from wild populations, is to be further analysed. A democratised online trade that is not bound to physical marketplaces might further mean that research has to refine its models of the songbird trade's supply chain (Jepson et al., 2011) and the typology of actors involved in illegal wildlife trade (Phelps et al., 2016).

We found that asking prices were not spatially autocorrelated, which supports our argument that what we observe might be a democratisation of the songbird trade. The trade seems to spread out into the countryside rather than concentrate itself in a few established markets in major cities (cf. Siriwat \& Nijman, 2020), without an apparent effect on prices. It is conceivable that has been the case before internet trade, owing to a traditional network of distributors and traders. However, we argue that a publicly observable online trade might well facilitate monitoring, compared to intricate distribution networks, the intermediary actors of which potentially overlap with various other legal and illegal networks.

Finally, we found a significant difference in online marketplace asking prices and prices stated in a consumer survey (Marshall et al., 2020a, Fig. 5). This might be attributable to a different set of species in the two datasets (the consumer data set does not distinguish by species), a prevalence to ask for higher prices to leave a bargaining margin on the side of sellers, or, on the buyers' side, a tendency to underestimate and understate the costs associated to a hobby, such as bird ownership. Higher asking prices might also account for the additional costs of a possible delivery to the transaction meeting point. Hobby breeders or pet holders selling "second-hand" birds might overestimate the commercial value of their merchandise. Further investigation will be necessary to constitute the causes of the observed price differences. With our findings in mind, future research should be careful to remain aware of the likely overestimation of prices derived from online data sources.

\subsection{Digital data come with biases but offer unique opportunities}

Data from online platforms is subject to some biases that are not as severe in data that is collected using more established scientific methods. Toivonen et al. (2019) as well as Wilkins et al. (2020) and Ghermandi and Sinclair (2019) discuss shortcomings and biases with a focus on social media data used for conservation science research. Most of their conclusions are equally applicable to our data sets. The data from YouTube suffer from noisiness and are likely biased towards certain user groups and geographic regions. In all likelihood, positive messages are more emphasised than negative ones (Reinecke \& Trepte, 2014). Crowdsourced citizen-science data is subject to many biases (Johnston et al., 2020), with factors such as accessibility, expected biodiversity and species charisma influencing which species citizen scientists report from where (Johnston et al., 2020). Our eBird data set exhibits an imbalance between species; only seven records represent the Javan pied starling. Considering that in the marketplace data the Javan pied starling is the species advertised for sale most often (Table 2), the low number of sightings is a valuable finding in itself, and confirms the paradox situation of "large-scale trade in a bird that is extinct in the wild" (Nijman et al., 2021). It seems to support the notion that rarity in the wild is a highly sought-after quality of songbirds (Harris et al., 2015). Whether the sought-after quality of rarity is based solely on rarity in the wild, and how much influence commercial availability has, cannot be answered here, and should be subject of a separate study. The data from the online marketplace platform OLX seem to suffer from fewer inherent biases, the predominant one being a bias towards an Internet-savvy, likely younger and more affluent population. Given that songbird pet-ownership rates are significantly higher in urban communities (Marshall et al., 2020a, 2020b), this bias might not weigh as heavy but rather constitute a focus onto a likely target audience.

Clear strengths of using online digital data sources to explore and investigate conservation issues are the temporal and spatial extent, coverage, resolution, and continuity of such data (Correia et al., 2021). Even though data access and precise data formats may change over time (Toivonen et al., 2019; Di Minin, Fink, et al., 2019), online data provide a previously unavailable opportunity for cost-efficient long-term monitoring of human actions that relate to conservation topics (Fink et al., 2020). In contrast to market surveys, online data do not relate to specific points in time and space (cf. Fig. 1 in Chng, Shepherd, \& Eaton, 2018), but can cover longer periods and larger areas without the significant costs associated to traditional surveys, something that has been called for in the case of the Indonesian songbird trade (Rentschlar et al., 2018). The breadth of online data, together with a modern toolbox of advanced statistics and artificial intelligence, can help distil observations down to the essential vantage points for nudging people towards more sustainable lifestyles.

\subsection{Future research should broaden the thematic and methodological scope}

Our study is limited by its small number of focal species, and by the temporal window of our data collection. Both can be easily overcome. The challenge of long-term data collection is mainly organisational. Very long-term data collection, such as the one by Nijman et al. (2018) that spans decades, might also require progressive adjustments to the data scraping algorithms. The limitation to a few species is due to the exploratory nature of our study. Experimental changes to our data collection workflow showed promising data yield also for other species, such as the rufous-fronted laughingthrush (Garrulax rufifrons), and for broader search terms such as "burung" ("bird"). A significant effort of any similar study will be to compile, expand, and test a suitable set of keywords.

Despite some biases that are typical for digital data sources (Kitchin, 2014; Toivonen et al., 2019), the advantages of using big data gathered from online sources are clear: data from online marketplaces provide detailed product descriptions, photos of the traded goods, asking prices and a location - without the effects an observer has on the observation and on the observed phenomenon in a traditional market survey (cf. Chng et al., 2015). Data relating to pet ownership, while not providing absolute numbers, give a good account of the relative popularity of different species, at different times, and in different places. Finally, data on animal sightings, such as, for instance, birdwatchers' observations, document actual locations of individuals of a species at a specific time, and, for certain applications, might offer advantages over species range maps. The insights gained in this study can be readily transferred to tap 
other data sources and investigate the trade in other species.

This study is using Euclidean, cartesian space as a reference framework, and assumes a positivist, "realist" perspective (Schuurman, 2006). We acknowledge that our analysis cannot appropriately grasp certain aspects such as the motivation of consumers and poachers, and the social and cultural functions of the songbird trade. Rather, our study forms the starting point for research that goes beyond the "view from above". It should be followed up with more qualitative research, to form an explanatory mixed-methods study (Creswell \& Creswell, 2018), that offers an in-depth investigation of buyers' and sellers' motivation and their level of awareness to biodiversity conservation issues to identify critical pivot points for a change in consumer demand.

\section{Conclusions}

In this study, we found trade in threatened songbirds on a traditional online marketplace platform, where it is tolerated presumably due to its deep cultural acceptance. Using web scraping tools, it was considerably easier to collect data from this platform than it would have been to collect similar data from (likely closed-access) social media groups. We argue that this form of online trade could turn out a blessing in disguise for conservation science: If the trade in endangered songbirds takes place on online marketplace platforms that are easy to monitor, conservation scientists, practitioners and policymakers have a readily accessible data source that can give rich insights into the spatial, temporal and taxonomic structure of such a trade, understand the motivations of buyers and sellers, and outline possibilities to move an illegal wildlife trade into more sustainable spheres even if it is a long-held and deeply-rooted cultural practice. Trade platforms might become valuable partners, for example, to alert potential buyers to the biodiversity conservation issues at hand or to establish certification schemes to transition to a more sustainable trade. Our proposed methods can be expanded to other platforms and species to investigate online trade in wildlife.

\section{Data availability}

Due to the focal species being under imminent threat of extinction, the eBird data set and derivations cannot be shared. It is, however, directly available from the Cornell Lab subject to undergoing their data request procedure. The data collected from the OLX marketplace and from the YouTube video platform can be downloaded in anonymised form from http://urn.fi/urn:nbn:fi:att:3e4b2f79-e073-4e64-8f0d-0a17 3 ad4ee9b, images and descriptions are available from the authors upon request.

\section{CRediT authorship contribution statement}

Christoph Fink: conceptualisation, methodology, formal analysis, investigation, software, data curation, visualisation, writing - original draft, writing - review and editing. Tuuli Toivonen: conceptualisation, writing - review and editing. Ricardo A. Correia: methodology, writing review and editing. Enrico Di Minin: conceptualisation, methodology, writing - review and editing.

\section{Declaration of competing interest}

None of the authors have a competing interest.

\section{Acknowledgements}

The authors want to express their thanks to Stuart Butchart, BildLife International, for his helpful directions and comments to an earlier version of the manuscript, and to Jenna Curtis at eBird for her help with difficult-to-find records on bird sightings. We also thank two anonymous reviewers for the careful review and constructive suggestions. C.F. thanks the University of Helsinki for a grant to E.D.M. T.T. thanks the
Osk. Huttunen Foundation, the KONE Foundation [grant number 086878], and Clare Hall College, Cambridge University, for support. R. A.C. thanks the Helsinki Institute of Sustainability Science (HELSUS) and the University of Helsinki for funding to E.D.M. E.D.M. and C.F. thank the European Research Council (ERC) for funding under the European Union's Horizon 2020 research and innovation program [grant agreement 802933].

\section{Appendix A. Supplementary data}

Supplementary data to this article can be found online at https://doi. org/10.1016/j.apgeog.2021.102505.

\section{References}

Aloysius, S. L. M., Yong, D. L., Lee, J. G., \& Jain, A. (2020). Flying into extinction: Understanding the role of Singapore's international parrot trade in growing domestic demand. Bird Conservation International, 30, 139-155. https://doi.org/10.1017/ S0959270919000182

Arribas-Bel, D., Garcia-López, M.-À., \& Viladecans-Marsal, E. (2019). Building(s and) cities: Delineating urban areas with a machine learning algorithm. Journal of Urban Economics, 103217. https://doi.org/10.1016/j.jue.2019.103217

Beastall, C., Shepherd, C. R., Hadiprakarsa, Y., \& Martyr, D. (2016). Trade in the helmeted hornbill rhinoplax vigil: The 'ivory hornbill. Bird Conservation International, 26, 137-146. https://doi.org/10.1017/S0959270916000010

Bergin, D., Chng, S. C. L., Eaton, J. A., \& Shepherd, C. R. (2018). The final straw? An overview of straw-headed bulbul Pycnonotus zeylanicus trade in Indonesia. Bird Conservation International, 28, 126-132. https://doi.org/10.1017/ S0959270917000302

Bird, S., Klein, E., \& Loper, E. (2012). Natural Language Processing with Python - Analyzing text with the Natural Language Toolkit (2nd ed.). NLTK (online) nltk.org/book/.

Birdlife International. (2017). Gracupica jalla: BirdLife International: The IUCN Red List of Threatened Species 2017: e.T103890801A118590020. https://doi.org/10.2305/ IUCN.UK.2017-3.RLTS.T103890801A118590020.en

BirdLife International. (2019). BirdLife international and Handbook of the birds of the World (2019) bird species distribution maps of the world. Version 2019.1.

Butchart, S. H. M., Walpole, M., Collen, B., van Strien, A., Scharlemann, J. P. W., Almond, R. E. A., Baillie, J. E. M., Bomhard, B., Brown, C., Bruno, J., Carpenter, K. E., Carr, G. M., Chanson, J., Chenery, A. M., Csirke, J., Davidson, N. C., Dentener, F., Foster, M., Galli, A., ... Watson, R. (2010). Global biodiversity: Indicators of recent declines. Science, 328, 1164-1168. https://doi.org/10.1126/ science.1187512

Carriere, D. (2013). Geocoder. geocoder.readthedocs.io.

Challender, D. W. S., \& MacMillan, D. C. (2014). Poaching is more than an Enforcement Problem. Conservation Letters, 7, 484-494. https://doi.org/10.1111/conl.12082

Chng, S. C. L., Eaton, J. A., Krishnasamy, K., Shepherd, C. R., \& Nijman, V. (2015). In the market for extinction: An inventory of jakarta's bird markets, TRAFFIC report.

Chng, S. C. L., Krishnasamy, K., \& Eaton, J. A. (2018). In the market for extinction: The cage bird trade in Bali. Forktail, 34, 35-41.

Chng, S. C. L., Shepherd, C. R., \& Eaton, J. A. (2018). In the market for extinction: Birds for sale at selected outlets in sumatra. Traffic Bulletin, 30.

Chollet, F., \& others. (2015). Keras. keras.io.

CITES. (2020). CITES Appendix I, version from August 2020.

Correia, R. A., Ladle, R., Jarić, I., Malhado, A. C. M., Mittermeier, J. C., Roll, U., SorianoRedondo, A., Veríssimo, D., Fink, C., Hausmann, A., Guedes-Santos, J., Vardi, R., \& Di Minin, E. (2021). Digital data sources and methods for conservation culturomics. forthcoming Conservation Biology. https://doi.org/10.1111/cobi.13706.

Creswell, J. W., \& Creswell, J. D. (2018). Research design: Qualitative, quantitative, and mixed methods approaches (5th ed.). Los Angeles: SAGE.

Dang Vu, H. N., \& Nielsen, M. R. (2021). Evidence or delusion: A critique of contemporary rhino horn demand reduction strategies. Human Dimensions of Wildlife, 26(4). https://doi.org/10.1080/10871209.2020.1818896

Deng, J., Dong, W., Socher, R., Li, L.-J., Li, K., \& Fei-Fei, L. (2009). ImageNet: A largescale hierarchical image database. In 2009 IEEE conference on computer vision and pattern recognition. IEEE. https://doi.org/10.1109/CVPR.2009.5206848.

Di Minin, E., Brooks, T. M., Toivonen, T., Butchart, S. H. M., Heikinheimo, V., Watson, J. E. M., Burgess, N. D., Challender, D. W. S., Goettsch, B., Jenkins, R., \& Moilanen, A. (2019). Identifying global centers of unsustainable commercial harvesting of species. Science Advances, 5, Article eaau2879. https://doi.org/ 10.1126/sciadv.aau2879

Di Minin, E., Fink, C., Hausmann, A., Kremer, J., \& Kulkarni, R. (2021). How to address data privacy concerns when using social media data in conservation science. Conservation Biology. https://doi.org/10.1111/cobi.13708

Di Minin, E., Fink, C., Hiippala, T., \& Tenkanen, H. (2019). A framework for investigating illegal wildlife trade on social media with machine learning. Conservation Biology, 33, 210-213. https://doi.org/10.1111/cobi.13104

Di Minin, E., Fink, C., Tenkanen, H., \& Hiippala, T. (2018). Machine learning for tracking illegal wildlife trade on social media. Nature Ecology \& Evolution, 2, 406-407. https://doi.org/10.1038/s41559-018-0466-X

Doxsey-Whitfield, E., MacManus, K., Adamo, S. B., Pistolesi, L., Squires, J., Borkovska, O., \& Baptista, S. R. (2015). Taking advantage of the improved availability of census data: A first look at the gridded population of the World, 
version 4. Pap. Applied Geography, 1, 226-234. https://doi.org/10.1080/ 23754931.2015.1014272

Eaton, J. A., Shepherd, C. R., Rheindt, F. E., Harris, J. B. C., van Balen, Wilcove, D. S., \& Collar, N. J. (2015). Trade-driven extinctions and near-extinctions of avian taxa in Sundaic Indonesia. Forktail, 31, 1-12.

Fahmi, H., Akbar, M. J., Rahadhian, I., Fadil, I., Ardiansyah, R. D., Ardian, I. F., Daiva, A. F., Abdurrohman, H., Kusuma, P. A., Razin, H., Isnadi, S., Suheri, H., Fahmi, T., Kholis, I. N., Alpian, A., Rokhman, N., Ramadhanty, S., Hamid, A., Hidajat, A. R., ... Kusumawati, R. (2019). NERGRIT: Open source corpus for Indonesian named entity recognition, sentiment analysis and statement extraction.

Fink, C. (2020a). olxsearch: Python script to download OLX small ads data. Zenodo. https://doi.org/10.5281/ZENODO.3906038

Fink, C. (2020b). metatube: Python script to download YouTube metadata. Zenodo. https://doi.org/10.5281/zenodo.3773302

Fink, C., Hausmann, A., \& Di Minin, E. (2020). Online sentiment towards iconic species. Biological Conservation, 108289. https://doi.org/10.1016/j.biocon.2019.108289

Ghermandi, A., \& Sinclair, M. (2019). Passive crowdsourcing of social media in environmental research: A systematic map. Global Environmental Change, 55, 36-47. https://doi.org/10.1016/j.gloenvcha.2019.02.003

Gunawan, A. P., \& Noske, R. A. (2017). The illegal trade of Indonesian raptors through social media. Kukila, 20, 1-11.

Harper, M., Weinstein, B., Simon, C., Morgan, W., Knight, V., Swanson-Hysell, N., Evans, M., Greco, M., \& Zuidhof, G. (2015). python-ternary: Ternary plots in Python. Zenodo. https://doi.org/10.5281/ZENODO.594435

Harris, J. B. C., Green, J. M. H., Prawiradilaga, D. M., Giam, X., Giyanto, Hikmatullah, D. Putra, C. A., \& Wilcove, D. S. (2015). Using market data and expert opinion to identify overexploited species in the wild bird trade. Biological Conservation, 187, 51-60. https://doi.org/10.1016/j.biocon.2015.04.009

Harris, J. B. C., Tingley, M. W., Hua, F., Yong, D. L., Adeney, J. M., Lee, T. M., Marthy, W., Prawiradilaga, D. M., Sekercioglu, C. H., Suyadi, Winarni, N., \& Wilcove, D. S. (2017). Measuring the impact of the pet trade on Indonesian birds: Bird declines from pet trade. Conservation Biology, 31, 394-405. https://doi.org/ 10.1111/cobi.12729

He, K., Zhang, X., Ren, S., \& Sun, J. (2016). Deep residual learning for image recognition. IEEE. https://doi.org/10.1109/CVPR.2016.90

Hinsley, A., \& 't Sas-Rolfes, M. (2020). Wild assumptions? Questioning simplistic narratives about consumer preferences for wildlife products. People Nat. https://doi. org/10.1002/pan3.10099. pan3.10099.

Hunter, J. D. (2007). Matplotlib: A 2D graphics environment. Computing in Science \& Engineering, 9, 90-95. https://doi.org/10.1109/MCSE.2007.55

Iqbal, M. (2015). Looking at online bird trading in Indonesia; a case study from South Sumatra. BirdingASIA, 24, 132-135.

IUCN. (2020a). The IUCN red list of threatened species. Version 2020-2.

IUCN. (2020b). IUCN red list of threatened species version March 2020: Species range map data.

Jepson, P. (2010). Towards an Indonesian bird conservation ethos: Reflections from a study of bird-keeping in the cities of Java and Bali. In S. Tidemann, \& A. Gosler (Eds.), Ethno-Ornithology: Birds, indigenous peoples, culture and society. London: Earthscan.

Jepson, P., \& Ladle, R. J. (2005). Bird-keeping in Indonesia: Conservation impacts and the potential for substitution-based conservation responses. Oryx, 39, 442. https:// doi.org/10.1017/S0030605305001110

Jepson, P., \& Ladle, R. J. (2009). Governing bird-keeping in Java and Bali: Evidence from a household survey. Oryx, 43, 364. https://doi.org/10.1017/S0030605309990251

Jepson, P., Ladle, R. J., \& Sujatnika. (2011). Assessing market-based conservation governance approaches: A socio-economic profile of Indonesian markets for wild birds. Oryx, 45, 482-491. https://doi.org/10.1017/S003060531100038X

Johnston, A., Moran, N., Musgrove, A., Fink, D., \& Baillie, S. R. (2020). Estimating species distributions from spatially biased citizen science data. Ecological Modelling, 422, 108927. https://doi.org/10.1016/j.ecolmodel.2019.108927

Jones, C. B., \& Purves, R. S. (2008). Geographical information retrieval. International Journal of Geographical Information Science, 22, 219-228. https://doi.org/10.1080/ 13658810701626343

Kitchin, R. (2014). Big Data, new epistemologies and paradigm shifts. Big Data \& Society, 1. https://doi.org/10.1177/2053951714528481, 205395171452848.

Kounadi, O., \& Resch, B. (2018). A geoprivacy by design guideline for research campaigns that use participatory sensing data. Journal of Empirical Research on Human Research Ethics, 20.

Lee, J. G. H., Chng, S. C. L., \& Eaton, J. A. (2016). Conservation strategy for Southeast Asian songbirds in trade. Singapore: Wildlife Reserves Singapore/TRAFFIC.

Leidner, J. L., \& Lieberman, M. D. (2011). Detecting geographical references in the form of place names and associated spatial natural language. SIGSPATIAL Spec, 3, 5-11. https://doi.org/10.1145/2047296.2047298
Leupen, B. T. C., Krishnasamy, K., Shepherd, C. R., Chng, S. C. L., Bergin, D., Eaton, J. A., Yukin, D. A., Hue, S. K. P., Miller, A., Nekaris, K. A.-I., Nijman, V., Saaban, S., \& Imron, M. A. (2018). Trade in White-rumped Shamas Kittacincla malabarica demands strong national and international responses. Forktail, 34, 8.

Marshall, H., Collar, N. J., Lees, A. C., Moss, A., Yuda, P., \& Marsden, S. J. (2020a). Characterizing bird-keeping user-groups on Java reveals distinct behaviours, profiles and potential for change. People Nat. https://doi.org/10.1002/pan3.10132

Marshall, H., Collar, N. J., Lees, A. C., Moss, A., Yuda, P., \& Marsden, S. J. (2020b). Spatio-temporal dynamics of consumer demand driving the Asian Songbird Crisis. Biological Conservation, 241, 108237. https://doi.org/10.1016/j. biocon.2019.108237

Maxwell, S. L., Fuller, R. A., Brooks, T. M., \& Watson, J. E. M. (2016). Biodiversity: The ravages of guns, nets and bulldozers. Nature, 536, 143-145. https://doi.org/ 10.1038/536143a

Ministry of Environment and Forestry, Republic of Indonesia. (2018). Regulation on protected plants and animals. P.20/2018.

Nijman, V., Campera, M., Ardiansyah, A., et al. (2021). Large-scale trade in a songbird that is extinct in the wild. Diversity, 13(6), 238. https://doi.org/10.3390/d13060238

Nijman, V., Langgeng, A., Birot, H., Imron, M. A., \& Nekaris, K. A. I. (2018). Wildlife trade, captive breeding and the imminent extinction of a songbird. Global Ecology and Conservation, 15, Article e00425. https://doi.org/10.1016/j.gecco.2018.e00425

Phelps, J., Biggs, D., \& Webb, E. L. (2016). Tools and terms for understanding illegal wildlife trade. Frontiers in Ecology and the Environment, 14, 479-489. https://doi.org/ 10.1002/fee.1325

Reinecke, L., \& Trepte, S. (2014). Authenticity and well-being on social network sites: A two-wave longitudinal study on the effects of online authenticity and the positivity bias in SNS communication. Computers in Human Behavior, 30, 95-102. https://doi. org $/ 10.1016 /$ j.chb.2013.07.030

Rentschlar, K. A., Miller, A. E., Lauck, K. S., Rodiansyah, M., \& Bobby, M. K. (2018). A silent morning: The songbird trade in Kalimantan, Indonesia. Tropical Conservation Science, 11. https://doi.org/10.1177/1940082917753909, 194008291775390.

Rey, S. J., \& Anselin, L. (2007). PySAL: A Python library of spatial Analytical methods. The Review of Regional Studies, 37, 5-27.

Schubert, E., Sander, J., Ester, M., Kriegel, H. P., \& Xu, X. (2017). DBSCAN revisited, revisited: Why and how you should (still) use DBSCAN. ACM Transactions on Database Systems, 42, 1-21. https://doi.org/10.1145/3068335

Schuurman, N. (2006). Formalization matters: Critical GIS and ontology research. Annals of the Association of American Geographers, 96, 726-739. https://doi.org/10.1111/ j.1467-8306.2006.00513.x

Shepherd, C. R., Eaton, J. A., \& Chng, S. C. L. (2016). Nothing to laugh about - the ongoing illegal trade in laughingthrushes ( Garrulax species) in the bird markets of Java, Indonesia. Bird Conservation International, 26, 524-530. https://doi.org/ $10.1017 /$ S0959270916000320

Siriwat, P. (2019). The role of the anthropogenic Allee effect in the exotic pet trade on Facebook in Thailand. Journal of Nature Conservation, 125726. https://doi.org/ 10.1016/j.jnc.2019.125726

Siriwat, P., \& Nijman, V. (2020). Wildlife trade shifts from brick-and-mortar markets to virtual marketplaces: A case study of birds of prey trade in Thailand. S2287884X2030042X Journal of Asia-Pacific Biodiversity. https://doi.org/10.1016/j. japb.2020.03.012.

Sodhi, N. S., Koh, L. P., Brook, B. W., \& Ng, P. K. L. (2004). Southeast Asian biodiversity: An impending disaster. Trends in Ecology \& Evolution, 19, 654-660. https://doi.org/ 10.1016/j.tree.2004.09.006

Sullivan, B. L., Wood, C. L., Iliff, M. J., Bonney, R. E., Fink, D., \& Kelling, S. (2009). eBird: A citizen-based bird observation network in the biological sciences. Biological Conservation, 142, 2282-2292. https://doi.org/10.1016/j.biocon.2009.05.006

Toivonen, T., Heikinheimo, V., Fink, C., Hausmann, A., Hiippala, T., Järv, O., Tenkanen, H., \& Di Minin, E. (2019). Social media data for conservation science: A methodological overview. Biological Conservation, 233, 298-315. https://doi.org/ 10.1016/j.biocon.2019.01.023

Virtanen, P., Gommers, R., Oliphant, T.E., Haberland, M., Reddy, T., Cournapeau, D., Burovski, E., Peterson, P., Weckesser, W., Bright, J., van der Walt, S.J., Brett, M., Wilson, J., Millman, K.J., Mayorov, N., Nelson, A.R.J., Jones, E., Kern, R., Larson, E., Carey, C.J., Polat, I., Feng, Y., Moore, E.W., VanderPlas, J., Laxalde, D., Perktold, J., Cimrman, R., Henriksen, I., Quintero, E.A., Harris, C.R., Archibald, A.M., Ribeiro, A. H., Pedregosa, F., van Mulbregt, P., SciPy 1.0 Contributors, 2020. SciPy 1.0: fundamental algorithms for scientific computing in Python. Nature Methods 17 , 261-272. https://doi.org/10.1038/s41592-019-0686-2.

Wilkins, E. J., Wood, S. A., \& Smith, J. W. (2020). Uses and limitations of social media to inform visitor use management in parks and protected areas: A systematic review. Environmental Management. https://doi.org/10.1007/s00267-020-01373-7

Yu, X., \& Jia, W. (2015). Moving targets: Tracking online sales of illegal wildlife products in China. TRAFFIC Brief. 